\title{
Biomedical Ethics
}

National Cancer Institute

\section{Source}

National Cancer Institute. Biomedical Ethics. NCI Thesaurus. Code C16340.

The branch of ethics that studies moral values in the biomedical sciences. 